\title{
Merkel cell polyomavirus (MCV) T-antigen seroreactivity, MCV DNA in eyebrow hairs, and squamous cell carcinoma
}

Shalaka S. Hampras ${ }^{1 *}$, Angelika Michel ${ }^{2}$, Markus Schmitt $^{2,3}$, Tim Waterboer $^{2}$, Lena Kranz ${ }^{2,4}$, Tarik Gheit ${ }^{5}$, Kate Fisher ${ }^{6}$, Vernon K. Sondak', Jane Messina ${ }^{7,8,9}$, Neil Fenske ${ }^{9,10}$, Basil Cherpelis ${ }^{9,10}$, Massimo Tommasino ${ }^{5}$, Michael Pawlita ${ }^{2}$ and Dana E. Rollison ${ }^{1}$

\begin{abstract}
Background: The role of Merkel cell polyomavirus (MCV) infection in the etiology of non-melanoma skin cancers, other than Merkel cell carcinoma, is unclear. Previously, we reported a significant association between seropositivity to MCV capsid antigen and MCV DNA-positive cutaneous squamous cell carcinoma (SCC). Here we present associations between SCC and seroreactivity to MCV T-antigen (T-Ag) oncoprotein, as well as MCV DNA detected in eyebrow hairs.

Findings: A clinic-based case-control study, including 171 SCC cases and 300 controls without skin cancer, was conducted at Moffitt Cancer Center in Tampa, Florida. Multiplex assays were used to measure serum antibodies against MCV small and large T-Ag and MCV DNA in both eyebrow hairs and SCC tumors $(n=144)$. Odds ratios (ORs) and $95 \%$ confidence intervals (Cls) were estimated using logistic regression to evaluate the associations between MCV and SCC. No significant association was observed between seroreactivity to MCV full-length large or small T-Ag and SCC, overall [OR $\mathrm{R}_{\text {large } \mathrm{T}-\mathrm{Ag}}=0.99(0.48-2.08), \mathrm{OR}_{\text {small }} \mathrm{T}-\mathrm{Ag}=0.31$ (0.06-1.62)] or when comparing tumor MCV DNA-positive cases to controls [OR large T-Ag $=1.06(0.38-2.93)]$. Only presence of MCV DNA in eyebrow hairs was significantly associated with MCV DNA-positive SCC [OR = 4.05 (2.01-8.18)].
\end{abstract}

Conclusion: MCV infection is unlikely to play a direct role in SCC.

Keywords: Merkel cell polyomavirus, Cutaneous squamous cell carcinoma, T-Antigen, Eyebrow hairs

\section{Findings}

\section{Introduction}

While Merkel cell polyomavirus (MCV) DNA has been consistently detected in more than $80 \%$ of Merkel cell carcinoma (MCC) [1-3], the role of MCV in the development of other non-melanoma skin cancers, such as cutaneous squamous cell carcinoma (SCC), is not established. Previously, two studies reported presence of MCV DNA in $0 \%$ of SCC tumors $[4,5]$, while six other studies showed MCV DNA in 13-38\% of SCC tumors [6-11]. The one study that examined oncoprotein expression [4]

\footnotetext{
* Correspondence: Shalaka.hampras@moffitt.org

'Department of Cancer Epidemiology, Moffitt Cancer Center, Tampa, FL 33612, USA

Full list of author information is available at the end of the article
}

reported no MCV T-antigen (T-Ag) expression in secondary SCCs detected among MCC patients.

In our previous case-control study, MCV DNA was detected in $38 \%$ of 145 SCC tumor tissues and significant association between seropositivity to MCV capsid antigen (VP1) and MCV DNA-positive SCC was observed [11]. However, given the high seroprevalence of viral capsid proteins in cancer free individuals [12], seropositivity to MCV capsid antigen may not reflect oncogenic viral infection and additional biomarkers of MCV infection should be explored.

Truncating mutations in $\mathrm{MCV}$ large $\mathrm{T}$-Ag C-terminus are thought to promote tumor cell proliferation [13]. While the oncogenic role of MCV T-Ag has been established in MCC [13, 14], SCC tumors lack the tumor promoting mutations in large $\mathrm{T}-\mathrm{Ag}$ observed in MCC [7]. 
Previous studies examining the role of MCV in SCC were limited by small sample size and only examined either MCV large T-Ag or VP1 protein sequence/expression in SCC $[4,7,8,6,9]$. We expanded our previous casecontrol analysis [11] to examine seroreactivity to both MCV large T-Ag and small T-Ag in association with SCC. Since serological response to MCV antigens may represent current and past infection and can possibly be affected by host factors associated with immune response, we also examined the association between MCV DNA present in eyebrow hairs and SCC.

\section{Materials and methods Study population}

The study population has been described in detail previously [11]. Briefly, a clinic-based case-control study was conducted at Moffitt Cancer Center, Tampa, Florida in 2007-2009. Cases included newly diagnosed, histologically confirmed cases of SCC, a majority of which were immunocompetent [11], and were identified through the University of South Florida (USF) Dermatology Clinic. Controls included patients without history of cancer and had a negative skin cancer screening exam at the USF Family Medicine Clinic or Moffitt's cancer screening clinic. Of the 173 SCC cases and 300 controls included in the MCV capsid antibody analysis [11], MCV T-Ag serology results were available for 171 SCC cases and 300 controls. Eyebrow hair samples were available for 169 SCC cases and 292 controls. All study participants completed a comprehensive questionnaire on demographics, lifestyle and skin cancer risk factors.

\section{Ethics, consent and permissions}

All participants provided written informed consent, and the study protocol was approved by the Institutional Review Board at USF.

\section{MCV serology}

Serum antibodies (IgG) to small T-Ag, full-length large T$\mathrm{Ag}$, large T-Ag exon 1 and large $\mathrm{T}-\mathrm{Ag}$ exon 2 of $\mathrm{MCV}$ (isolate 344) were measured using a fluorescent beadbased multiplex assay, as described previously $[15,11,16]$. Briefly, seroreactivity to MCV T-Ag was expressed as median fluorescence intensity (MFI). The cut-offs for seropositivity were determined using an independent reference sample of $42 \mathrm{MCC}$ patients (200 MFI for small T-Ag, 200 MFI for large T-Ag exon 1,400 MFI for large T-Ag exon 2 and 400 MFI for full-length large T-Ag).

\section{DNA measurement in SCC tumor tissues}

As described previously, MCV DNA from eyebrow hairs and fresh frozen SCC tumor tissue was detected using a highly sensitive and specific assay which combines multiplex polymerase chain reaction (PCR) and bead-based
Luminex technology $[11,17]$. MCV viral load (absolute copy number per sample) in SCC tumor tissue was determined using a multiplex quantitative real-time PCR targeting the $\mathrm{N}$-terminus and $\mathrm{C}$-terminus of the MCV Tantigen sequence [18]. The ratio of $\mathrm{N}$-terminus to Cterminus copy numbers of MCV DNA was determined to examine the presence of C-terminus deletions. Two samples of formalin fixed paraffin embedded MCC tumor tissues were analyzed as positive controls. Data on both MCV T-Ag serology and MCV tumor DNA were available from 144 SCC cases, while data on MCV DNA in eyebrow hair and MCV DNA in SCC tumor were available from 141 SCC cases.

\section{Statistical analysis}

Associations between MCV T-Ag seropositivity, MCV DNA in eyebrow hairs and SCC were estimated by odds ratios (OR) and $95 \%$ confidence intervals $(\mathrm{CI})$ calculated using logistic regression with adjustment for age and gender. Odds ratios were calculated separately for $\mathrm{MCV}$ DNA-positive SCC cases and MCV DNA-negative SCC cases using multinomial logistic regression, also adjusting for age and gender. Analyses were conducted using SAS software, version 9.3 (SAS institute Inc., Cary, North Carolina) and R software, version 2.15.1 [19].

\section{Results}

Demographic characteristics of the study population and factors associated with SCC have been described previously [11]. Cases (mean age $=64.4$, standard deviation $=9.9$ ) were significantly older compared to controls (mean age $=55.4$, standard deviation $=11.7$, $\mathrm{p}$ value $=<0.0001)$, and were more likely to be males $(65.9 \%)$ compared to controls $(38.0 \%, \mathrm{P}$ value $=<0.0001)[11]$. As seen in Table 1, $0.3-1 \%$ of controls and $0-1.2 \%$ of SCC cases were seropositive to MCV T-Ags based on MFI cut-offs determined using a reference sample of MCC cases. Due to the small number of seropositive cases and controls, robust statistical analyses to examine age-adjusted association of MCV seropositivity with SCC could not be conducted. Hence, a less stringent cut-off of $>50$ MFI for seropositivity was used and no significant associations between seropositivity to any of the MCV antigens and SCC were observed, after adjusting for age and gender (Table 1). MCV DNA was present in eyebrow hairs for $37.3 \%$ of controls and $48.5 \%$ of SCC cases, a difference that was not statistically significant (Table 1).

When analyses were stratified by the presence of MCV DNA in SCC tumors, no associations were observed with seroreactivity to MCV large T-Ag (Table 2). A statistically significant four-fold association was observed between the presence of MCV DNA in eyebrow hairs and $\mathrm{MCV}$ DNA-positive SCC versus controls $(\mathrm{OR}=4.05,95 \% \mathrm{CI}$ 
Table 1 Associations between Merkel cell polyomavirus and cutaneous squamous cell carcinoma

\begin{tabular}{|c|c|c|c|c|c|c|}
\hline \multirow[t]{3}{*}{ MCV biomarker } & Controls & SCC Cases & Controls & SCC Cases & \multirow[t]{3}{*}{ OR $(95 \% \mathrm{Cl})$} & \multirow[t]{3}{*}{$p$-value } \\
\hline & $N=300$ & $N=171$ & $N=300$ & $N=171$ & & \\
\hline & n (\%) & n (\%) & n (\%) & n (\%) & & \\
\hline Seropositivity to MCV T-Ag & \multicolumn{2}{|c|}{ Cut points based on reference sample* } & \multicolumn{2}{|c|}{ Cut point of $>50 \mathrm{MFI}$} & & \\
\hline MCV small T & $1(0.3)$ & $0(0)$ & $7(2.3)$ & $2(1.2)$ & $0.31(0.06-1.62)$ & 0.164 \\
\hline MCV large T exon 1 & $2(0.7)$ & $0(0)$ & $3(1)$ & $1(0.6)$ & $0.56(0.05-5.93)$ & 0.633 \\
\hline MCV large T exon 2 & $2(0.7)$ & $1(0.6)$ & $18(6)$ & $16(9.4)$ & $1.22(0.57-2.62)$ & 0.611 \\
\hline \multirow[t]{3}{*}{ MCV large T } & $3(1.0)$ & $2(1.2)$ & $22(7.3)$ & $16(9.4)$ & $0.99(0.48-2.08)$ & 0.988 \\
\hline & & & Controls $(n=292)$ & Cases $(n=169)$ & OR $(95 \% \mathrm{Cl})$ & $p$-value \\
\hline & & & $n(\%)$ & $n(\%)$ & & \\
\hline Presence of MCV DNA in eyebrow hairs & & & 109 (37.3) & $82(48.5)$ & $1.17(0.76-1.78)$ & 0.478 \\
\hline
\end{tabular}

MCV Merkel cell polyomavirus, SCC cutaneous squamous cell carcinoma. *MFI cutoff for seropositivity based on MCC patients: 200 for small T, 200 for large T exon 1,400 for large T exon 2 and 400 for large T. Odds ratios (OR) and Wald $95 \%$ confidence intervals (CI) calculated using alternative cutoff of $>50$ MFI and logistic regression, adjusting for age and gender

$=2.01-8.18)$, while no association was observed with MCV DNA-negative SCC versus controls $(\mathrm{OR}=0.58$, $95 \%$ CI $=0.34-1.01$ ) (Table 2).

Overall, MCV copy numbers were lower for SCC compared to the two MCC tumor samples analyzed (Fig. 1). The ratio of $\mathrm{C}$ - to $\mathrm{N}$-terminus of all SCC samples was close to 1.0 , indicating the presence of full-length large T-Ag.

\section{Discussion}

In this clinic based case-control study, no significant association was observed between seropositivity to MCV T-Ag and SCC, overall or after stratifying by MCV DNA status in SCC tumor tissues. Interestingly, a greater than four-fold significant association was observed between MCV DNA positivity in eyebrow hairs and MCV DNA positive-SCC, although it should be noted that MCV viral DNA load was low in SCC tumors, with all exhibiting less than one viral copy per tumor cell.
Previously, in the same study population, we observed a greater than two-fold association between MCV DNApositive SCC and seropositivity to the MCV capsid antigen, VP1 [11]. However, in our previous study [11], $73.3 \%$ controls and $80.9 \%$ SCC cases were seropositive for VP1. In contrast, we report here $<2 \%$ of cases and controls were seropositive for MCV large T-Ag using the cut-off derived from MCC patients. As discussed previously [16], unlike viral capsid proteins, MCV T-Ags are located within the nucleus and are less likely to stimulate a serological response unless the $\mathrm{T}$-Ag is expressed in tumors. While T-Ag DNA sequences have been detected in MCV-positive SCC tumor tissues [6], their expression has not been observed in SCC tumor tissues arising in MCC patients [4] or in immunocompetent SCC cases [7]. This could explain the lower seroprevalence of MCV T-Ag observed among SCC cases compared to that of viral capsid antigens, as well as the

Table 2 Associations between Merkel cell polyomavirus and cutaneous squamous cell carcinoma by tumor MCV DNA status

\begin{tabular}{|c|c|c|c|c|c|c|}
\hline \multirow[b]{2}{*}{ MCV biomarker } & \multirow{2}{*}{$\begin{array}{l}\text { Controls } \\
(N=300) \\
n(\%)\end{array}$} & \multicolumn{2}{|c|}{$\begin{array}{l}\text { MCV tumor-negative SCC cases } \\
(N=89)\end{array}$} & \multicolumn{2}{|c|}{$\begin{array}{l}\text { MCV tumor-positive SCC cases } \\
(N=55)\end{array}$} & \multirow[t]{2}{*}{$p$-value } \\
\hline & & $\overline{\mathrm{n}(\%)}$ & $\mathrm{OR}(95 \% \mathrm{Cl})^{*}$ & $\overline{n(\%)}$ & OR $(95 \% \mathrm{Cl})^{*}$ & \\
\hline \multicolumn{7}{|l|}{ Seropositivity to MCV T-Ag (>50 MFI) } \\
\hline MCV small T-Ag & $7(2.3)$ & $2(2.2)$ & $0.63(0.12-3.32)$ & $0(0)$ & Could not be estimated & 0.862 \\
\hline MCV large T-Ag exon 1 & $3(1.0)$ & $1(1.1)$ & $1.11(0.11-11.61)$ & $0(0)$ & Could not be estimated & 0.996 \\
\hline MCV large T-Ag exon 2 & $18(6)$ & $10(11.2)$ & $1.50(0.63-3.53)$ & $5(9.1)$ & $1.06(0.35-3.2)$ & 0.640 \\
\hline \multirow[t]{4}{*}{ MCV large T-Ag } & $22(7.3)$ & $9(10.1)$ & $1.10(0.47-2.6)$ & $6(10.9)$ & $1.06(0.38-2.93)$ & 0.975 \\
\hline & Controls & \multirow{2}{*}{\multicolumn{2}{|c|}{$\begin{array}{l}\text { MCV-DNA negative SCC cases } \\
(n=86)\end{array}$}} & \multirow{2}{*}{\multicolumn{2}{|c|}{$\begin{array}{l}\text { MCV-DNA positive SCC cases } \\
(n=55)\end{array}$}} & \multirow[t]{3}{*}{$p$-value } \\
\hline & $(n=292)$ & & & & & \\
\hline & & n (\%) & OR $(95 \% \mathrm{Cl})^{*}$ & n (\%) & OR $(95 \% \mathrm{Cl})^{*}$ & \\
\hline MCV DNA present in eyebrow hairs & 109 (37.3) & $26(30.2)$ & $0.58(0.34-1.01)$ & $42(76.4)$ & $4.05(2.01-8.18)$ & $1.06 \times 10^{-6}$ \\
\hline
\end{tabular}




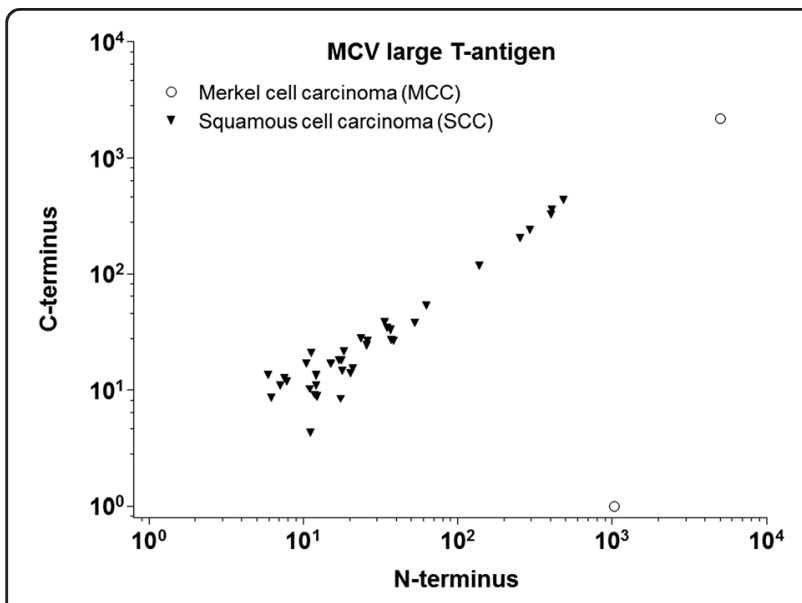

Fig. 1 Merkel cell polyomavirus DNA load in squamous cell carcinoma and merkel cell carcinoma tumor tissues. Absolute copy numbers of MCV DNA ( $\mathrm{N}$-terminus ( $\mathrm{X}$-axis) and $\mathrm{C}$-terminus ( $\mathrm{Y}$-axis) sequence) per sample of cutaneous squamous cell carcinoma (filled triangles) detected using multiplex GPCR (without beta globin) are shown. MCV DNA copy numbers in two merkel cell carcinoma samples (empty circles) are also shown. Overall, MCV DNA copy numbers were lower in squamous cell carcinoma samples than in merkel cell carcinoma. There was no indication of C-terminal deletion of T-antigen in MCV detected in squamous cell carcinoma samples

lower seroprevalence of MCV T-Ag in SCC cases compared to that reported among MCC cases [16].

The lack of an association between seropositivity to MCV T-Ag and SCC, and low viral DNA load in SCC tumors, suggest that MCV is not directly involved in the development of SCC. Further, the ratio of N-terminus to C-terminus of MCV T-Ag was close to 1.0 in $\mathrm{MCV}$ DNA-positive SCC (Fig. 1), indicating a lack of the tumor-promoting, signature T-Ag mutations described for MCC. Despite the lack of evidence for a causal role of MCV in SCC, an indirect role of MCV cannot be ruled out. In the present study, a four-fold association was observed between the presence of MCV DNA in eyebrow hairs and MCV DNA-positive SCC. This strong association, consistent with our previous report of a positive association between MCV seropositivity to capsid antigen and MCV DNA-positive SCC [11], suggests MCV may be a marker of an unknown immunological factor associated with SCC, acting either synergistically with or independently of MCV infection. However, in this retrospective case-control study, it is not possible to distinguish between immunological factors that predispose to SCC versus those that result from the presence of the cancer itself. A prospective study examining MCV infection in multiple biospecimens prior to the onset of SCC and markers of immune function is needed to elucidate the precise role of MCV in SCC.

\section{Abbreviations}

MCC: Merkel cell carcinoma; MCV: Merkel cell polyomavirus; SCC: Squamous cell carcinoma; VP1: Capsid antigen; T-Ag: T-antigen; MFI: Median fluorescence intensity; PCR: Polymerase chain reaction; OR: Odds ratios; $\mathrm{Cl}$ : Confidence intervals.

\section{Competing interests}

The authors declare that they have no competing interests.

\section{Authors' contributions}

SH: Drafted and revised the manuscript; AM and LK: conducted laboratory assays; MS, TW and MP: conducted and analyzed serological and tumor assays, provided insight into the interpretation of results, provided feedback on the manuscript; TG: conducted eyebrow hair assays, provided feedback on the manuscript; MT: conducted eyebrow hair assays, reviewed the manuscript; KF: conducted statistical analyses, provided feedback on the manuscript; VS: contributed to study design and data collection; JM: contributed to study design; NF and BC: contributed to data collection; DR: conceived and implemented the study design, collected data, provided insight into the analysis and interpretation of results, provided feedback on the manuscript. All authors have approved the final version of the manuscript.

\section{Acknowledgements}

This study was supported by a James and Esther King New Investigator grant awarded to D.E. Rollison by the Florida Department of Health (FL $\mathrm{DOH})$. The FL DOH had no involvement in the study design, collection, analysis or interpretation of the data, writing of the report, or decision to submit the paper for publication. The authors thank the staff of the Lifetime Cancer Screening clinic and USF Clinics for their assistance with recruitment of patients, especially Kristen Jonathan, Jill Weber, and Carolyn Gerow. The authors also thank Melissa Crochunis for assistance with the pathology reports. The authors state no conflict of interest.

\section{Author details}

'Department of Cancer Epidemiology, Moffitt Cancer Center, Tampa, FL 33612, USA. IInfection and Cancer Program, German Cancer Research Center, Heidelberg, Germany. ${ }^{3}$ Present address: GATC Biotech AG, Constance, Germany. ${ }^{4}$ Present address: Research Center for Immunotherapy (FZI), Langenbeckstrasse 1, Building 708, 55131 Mainz, Germany. ${ }^{5}$ Infections and Cancer Biology Group, International Agency for Research on Cancer-World Health Organization, Lyon 69372, France. ${ }^{6}$ Department of Biostatistics and Bioinformatics, Moffitt Cancer Center, Tampa, FL, USA. ${ }^{7}$ Cutaneous Oncology Program, Moffitt Cancer Center, Tampa, FL, USA. ${ }^{8}$ Departments of Pathology and Cell Biology, University of South Florida College of Medicine, Tampa, FL, USA. ${ }^{9}$ Dermatology, University of South Florida College of Medicine, Tampa, FL, USA. ${ }^{10}$ Cutaneous Surgery, University of South Florida College of Medicine, Tampa, FL, USA.

Received: 8 July 2015 Accepted: 27 August 2015

Published online: 19 October 2015

\section{References}

1. Chun SM, Yun SJ, Lee SC, Won YH, Lee JB. Merkel cell polyomavirus is frequently detected in korean patients with merkel cell carcinoma. Ann Dermatol. 2013;25(2):203-7.

2. Hattori T, Takeuchi Y, Takenouchi T, Hirofuji A, Tsuchida T, Kabumoto T, et al. The prevalence of Merkel cell polyomavirus in Japanese patients with Merkel cell carcinoma. J Dermatol Sci. 2013;70(2):99-107.

3. Paolini F, Donati P, Amantea A, Bucher S, Migliano E, Venuti A. Merkel cell polyomavirus in Merkel cell carcinoma of Italian patients. Virol J. 2011:8(103):8-103.

4. Reisinger DM, Shiffer JD, Cognetta Jr AB, Chang Y, Moore PS. Lack of evidence for basal or squamous cell carcinoma infection with Merkel cell polyomavirus in immunocompetent patients with Merkel cell carcinoma. J Am Acad Dermatol. 2010;63(3):400-3.

5. Ridd K, Yu S, Bastian BC. The presence of polyomavirus in non-melanoma skin cancer in organ transplant recipients is rare. J Invest Dermatol. 2009;129(1):250-2. doi:10.1038/jid.2008.215. Epub 2008 Jul 24.

6. Dworkin AM, Tseng SY, Allain DC, Iwenofu OH, Peters SB, Toland AE. Merkel cell polyomavirus in cutaneous squamous cell carcinoma of immunocompetent individuals. J Invest Dermatol. 2009;129(12):2868-74. 
7. Mertz KD, Paasinen A, Arnold A, Baumann M, Offner F, Willi N, et al. Merkel cell polyomavirus large $T$ antigen is detected in rare cases of nonmelanoma skin cancer. J Cutan Pathol. 2013;40(6):543-9.

8. Murakami M, Imajoh M, Ikawa T, Nakajima H, Kamioka M, Nemoto Y, et al. Presence of Merkel cell polyomavirus in Japanese cutaneous squamous cell carcinoma. J Clin Virol. 2011;50(1):37-41.

9. Scola N, Wieland U, Silling S, Altmeyer P, Stucker M, Kreuter A. Prevalence of human polyomaviruses in common and rare types of non-Merkel cell carcinoma skin cancer. Br J Dermatol. 2012;167(6):1315-20.

10. Imajoh M, Hashida Y, Nakajima H, Sano S, Daibata M. Prevalence and viral DNA loads of three novel human polyomaviruses in skin cancers from Japanese patients. J Dermatol. 2013;20(10):1346-8138.

11. Rollison DE, Giuliano AR, Messina JL, Fenske NA, Cherpelis BS, Sondak VK, et al. Case-control study of Merkel cell polyomavirus infection and cutaneous squamous cell carcinoma. Cancer Epidemiol Biomarkers Prev. 2012;21(1):74-81

12. Zhang C, Liu F, He Z, Deng Q, Pan Y, Liu Y, et al. Seroprevalence of Merkel cell polyomavirus in the general rural population of Anyang, China. PLoS One. 2014;9(9):e106430.

13. Shuda M, Feng H, Kwun HJ, Rosen ST, Gjoerup O, Moore PS, et al. T antigen mutations are a human tumor-specific signature for Merkel cell polyomavirus. Proc Natl Acad Sci U S A. 2008;105(42):16272-7.

14. Houben R, Adam C, Baeurle A, Hesbacher S, Grimm J, Angermeyer S, et al. An intact retinoblastoma protein-binding site in Merkel cell polyomavirus large $T$ antigen is required for promoting growth of Merkel cell carcinoma cells. Int J Cancer. 2012;130(4):847-56.

15. Waterboer T, Sehr P, Michael KM, Franceschi S, Nieland JD, Joos TO, et al. Multiplex human papillomavirus serology based on in situ-purified glutathione s-transferase fusion proteins. Clin Chem. 2005;51(10):1845-53.

16. Paulson KG, Carter JJ, Johnson LG, Cahill KW, lyer JG, Schrama D, et al. Antibodies to merkel cell polyomavirus $T$ antigen oncoproteins reflect tumor burden in merkel cell carcinoma patients. Cancer Res. 2010;70(21):8388-97.

17. Gheit T, Billoud G, de Koning MN, Gemignani F, Forslund O, Sylla BS, et al. Development of a sensitive and specific multiplex PCR method combined with DNA microarray primer extension to detect Betapapillomavirus types. J Clin Microbiol. 2007:45(8):2537-44. doi:10.1128/jcm.00747-07.

18. Schmitt M, Wieland U, Kreuter A, Pawlita M. C-terminal deletions of Merkel cell polyomavirus large T-antigen, a highly specific surrogate marker for virally induced malignancy. Int J Cancer. 2012;131(12):2863-8.

19. Team RC. R: A language and environment for statistical computing. Vienna, Austria: R Foundation for Statistical Computing; 2013. http://www.R-project.org/.

\section{Submit your next manuscript to BioMed Central and take full advantage of:}

- Convenient online submission

- Thorough peer review

- No space constraints or color figure charges

- Immediate publication on acceptance

- Inclusion in PubMed, CAS, Scopus and Google Scholar

- Research which is freely available for redistribution 